\title{
Pobreza y desigualdad social en Latinoamérica y el Caribe: dimensiones, complejidades y desafíos
}

Poverty and social inequality in Latin America and the Caribbean: dimensions, complexities and challenges

Nombre:

Filiación:

País:

Correo:

\author{
Dra. Sonia Pérez Tello ( $\left.{ }^{1}\right)$ \\ Universidad de Chile \\ Chile \\ sonperez@u.uchile.cl
}

\section{EDITORIAL}

La pregunta por las dimensiones de la pobreza y la desigualdad en Chile y América Latina, se instala como una obligación política y ética que la academia ha intentado responder de distintas formas. Tradicionalmente, los esfuerzos han estado puestos en la definición e identificación de aquel sector de la población denominado como "pobre", atendiendo a las características y componentes que describen la pobreza como fenómeno, lo que ha traído consigo una profunda discusión sobre cuáles son las necesidades, carencias o deprivaciones que dan cuenta de manera más justa con las diversas situaciones de exclusión y marginalidad social presentes en la región, como también la forma en que éstas se manifiestan.

\footnotetext{
${ }^{1}$ Doctora en Psicología Social y del Desarrollo de la Università Cattolica del Sacro Cuore di Milano, Italia. Académica del Departamento de Psicología de la Universidad de Chile y Directora de Investigación de la Facultad de Ciencias Sociales de la misma universidad. Es además Investigadora Responsable (s) del Núcleo Milenio "Centro de Investigación en Vulnerabilidades y Desastres Socionaturales" de la Universidad de Chile.
} 


\section{s\&e \\ SOCIEDADEEQUIDAD}

Sin embargo, la sola descripción de la pobreza, por más detallada que ésta pretenda ser, ha demostrado sucumbir a las exigencias sociales de erradicación y transformación social, indispensables en el camino de las sociedades hacia sistemas más justos e igualitarios. Tanto para las políticas sociales como para las ciencias que pretenden comprender los procesos de reproducción y transformación social, la explicación de la falta de ingresos socioeconómicos es insuficiente ante la dinámica y polifacética expresión de empobrecimientos, vulnerabilidades e indignas desigualdades que habitan las experiencias en sociedad.

Los problemas de la pobreza y la desigualdad, pertinazmente presentes en Chile y América Latina, continúan siendo un campo de interrogantes instaladas desde enfoques distintos, que poco dialogan entre sí y que, muchas veces, se prestan a inadecuadas evaluaciones de supuestos avances o retrocesos en el área.

Ciertamente, desde las ciencias sociales y económicas se ha avanzado en integrar otras dimensiones, distintas a la monetaria, en la explicación de la pobreza, principalmente cuando se trata de su medición. La pobreza entendida como carencias o necesidades básicas insatisfechas ha dado paso a nuevas definiciones centradas en recursos, activos $\mathrm{y} / \mathrm{o}$ capacidades no realizadas, desarticuladas o vulneradas en sus derechos. Propuestas de comprensión que exigen nuevos análisis, más complejos, interdisciplinarios, transectoriales, que alumbren tanto nuevas formas de medición como de evaluación e intervención.

Las dimensiones llamadas a explicar las nuevas y modernas formas de reproducción de pobreza y desigualdades, en nuestras sociedades, varían en sus niveles. Si intentamos responder "quién es pobre hoy", las dimensiones principalmente estudiadas son las áreas de vida o espacios de bienestar, que se encuentran deprimidos y carenciados en un contexto de desprotección social y debilitamiento de los vínculos estructurales. Así la educación, el empleo, la participación, la salud o la vivienda, son dimensiones por excelencia explicativas de la pobreza humana.

No obstante, si se quiere además responder a "cómo se (re)produce la pobreza y la desigualdad en nuestras sociedades", son llamadas a escena dimensiones mucho menos elaboradas por las políticas transnacionales de medición y mucho más habitadas en las tradiciones de la investigación social. Se evoca entonces a las prácticas sociales, los campos simbólicos de interacción en la estructura, el sujeto y su vida cotidiana, los modos de uso del tiempo y del espacio, las condiciones de ejercicio de los derechos humanos, entre otras.

El quinto número de Revista Sociedad y Equidad viene a alimentar de manera importante los conocimientos sobre los problemas de la pobreza y la desigualdad, precisamente a partir de estudios que ofrecen nuevas dimensiones de 


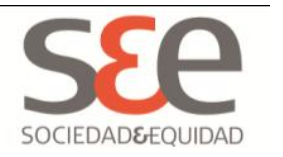

análisis. Los artículos invitan, desde distintos sectores de la región, a asumir la problemática de la pobreza y la desigualdad social como un fenómeno complejo, históricamente situado, de interacción entre dimensiones subjetivas, culturales, éticas, económicas y estructurales.

El recorrido se abre con una revisión histórica sobre los enfoques de medición de la pobreza en América Latina, que reposiciona el lugar de la región en las llamadas nuevas propuestas de medición multidimensional, cuestionando así la orientación política de los esfuerzos por delimitar la pobreza de la no pobreza. Avanzando en la mirada crítica de la multidimensionalidad, se propone luego la integración de los derechos humanos enfocados a la población infantil, mientras los siguientes autores analizan las implicancias de considerar la dimensión social en contextos de pobreza estructural. La discusión sobre los alcances del problema avanza en la discusión de nuevos enfoques de comprensión, abordando el desafío de integrar la libertad humana consecuentemente al enfoque de capacidades, en un marco de democracia, como también el de medir las variables de la vulnerabilidad social en localidades específicas, más allá de las características socioeconómicas.

Los textos permiten analizar dos vertientes de las dimensiones de la pobreza. Una mirada a las condiciones legales y estructurales de las políticas y programas sociales y otra más bien orientada a la vida en pobreza. En esta última línea se encontrarán artículos que revisan las dimensiones que afectan la vida cotidiana de mujeres y familia, tales como el uso del tiempo, la alimentación, el andar cotidiano en situaciones de calle y la naturalización de la corrupción.

Trabajos de México, Argentina, Brasil, Colombia y Chile se integran en este número para servir de aporte a un debate que, más que acabar, insiste en ser comprometidamente ampliado. 